\title{
Pengaruh Metode Latihan High Intensity Interval Training (HIIT) dalam Meningkatkan Power Otot Tungkai dan kelincahan pada Permainan Bola Voli
}

\author{
Linda Susila \\ Program studi Pendidikan Jasmani Kesehatan dan Rekreasi, STKIP Yapis Dompu \\ E-mail corresponding: susilalinda36@gmail.com
}

Article History: Received: 2021-07-22 || Revised: 2021-07-28 || Published: 2021-08-30

Sejarah Artikel : Diterima: 2021-07-22 || Direvisi: 2021-07-28 || Dipublikasi: 2021-08-30

\begin{abstract}
The type of research used is experimental research with a quantitative approach, this research is to find the effect of certain treatments on others under controlled conditions, the results show that high intensity interval training exercises with regular training methods can improve volleyball smash jump skills and agility movement in volleyball games, the target in this study was an exercise that was tested on 30 students of SMAN 1 Woja with a one group pretest-posttest design. The data were analyzed quantitatively with a quasiexperimental approach. And data analysis using the SPSS 21 application. And the results of leg muscle power $80 \%$ and movement agility $75 \%$. The conclusion of this study is that the high intensity interval training method is feasible to increase volleyball smash jumps and agility in volleyball games for students. SMAN 1 Woja. Thus a regular training program can provide excellent additional training for players and can further improve the quality and quantity.
\end{abstract}

Keywords: HIIT, Muscles, Legs, Agility

\begin{abstract}
Abstrak
Jenis penelitian yang di gunakan adalah penelitian eksperimen pendekatan kuantitatif, penelitian ini guna mencari pengaruh perlakuan tertentu terhadap yang lain dalam kondisi yang terkendali, hasil penelitian menunjukan bahwa latihan high intensity interval training dengan metode latihan yang secara teratur untuk dapat meningkatkan kemampuan lompatan smash bola voli dan kelincahan gerak dalam permainan bola voli, sasaran dalam penelitian ini adalah latihan yang di uji cobakan pada 30 siswa SMAN 1 Woja dengan rancangan one group pretest-posttest design. Data di analisa secara kuantitatif dengan pendekatan eeksperimen semu. Dan data analisis dengan mengunakan aplikasi SPSS 21. Dan hasil power otot tungkai 80\% dan kelincahan gerak 75\%, Simpulan pada penelitian ini adalah bahwa metode latihan high intensity interval training layak untuk meningkatkan lompatan smash bola voli dan kelincahan gerak dalam permainan bola voli pada siswa SMAN 1 Woja . dengan demikian program latihan yang teratur bisa memberikan tambahan latihan yang sangat baik untuk pemain bisa lebih meningkatkan lagi kualitas dan kuantitasnya.
\end{abstract}

Kata kunci: HIIT, Otot, Tungkai, Kelincahan

\section{PENDAHULUAN}

Olah raga permainan bola voli merupakan salah satu jenis dari cabang olahraga yang di mainkan oleh dua Tim yang berlawanan dengan mengunakan bola sebagai salah satu alat yang utama untuk bermain, olah raga ini juga memiliki dua jenis permainan yang terdiri dari voli umum dan voli pantai, pada jenis umum permainan bola voli di perankan oleh anggota yang berjumlahkan dua belas orang anggota, dengan pemain cadangan dan libero sebagai penganti spaiker ketika sudah keluar dari garis serang, di banding dengan jenis voli pantai yaitu dengan berjumlah anggotakan dua orang tanpa ada pemain cadangan, olahraga bola voli semakin banyak di mainkan tiap tahun untuk bisa melihat potensi dan kemajuan pemain-pemain baru maupun pemain lama, dalam membina dan mendidik pemain tidak jauh dari peran PBVSI maupun pelatih-pelatih yang ada.

Menurut Yudasmara (2014) "bahwa teknik dasar bola voli merupakan unsur yang sangat penting dalam permainan bola voli, tanpa penguasaan teknik dasar yang baik, maka permainan tidak akan sempurna, dalam olah raga permainan bola voli ada banyak teknik yang harus di kuasai oleh pemain sehingga akan membawa pemain menjadi pemain yang terbaik, pemain di tuntut untuk 
bisa menguasai beberapa teknik dalam permainan bola voli, dalam penguasaan teknik pemain akan di berikan beberapa latihan. latihan gerakan adalah latihan Squat jump untuk meningkatkan power otot tungkai dan zig-zag untuk meningkatkan kelincahan.

Siswa maupun siswi SMA Negeri 1 Woja antusias bangat mengikuti ekstrakurikuler sekolah sehingga tak jarang siswa di sekolah banyak memiliki prestasi pada cabang olahraga yang baik, sehingga pelajaran olah ragapun menjadi pelajaran favorit bagi mereka salah satunya pada cabang bola voli, SMA Negeri 1 Woja banyak yang menjadikan siswa-siswi nya pemain voli yang memiliki talenta-ralenta terbaik sehingga merekapun selalu mengikuti ajang turnamen bola voli antar sekolah, SMA 1 Woja selalu mendominan dalam permainan bola voli dengan demikian SMA 1 Woja selalu mendapatkan juara baik juara 2,3 maupun juara satu, pada pertandingan yang diselenggarakan SMA Negeri 2 dompu pada tahun lalu SMA Negeri 1 Woja mampu mengungguli sekolah-sekolah lain, sehingga mereka menjuarai turnamen voli tersebut, tapi yang menjadi kendala mereka pada saat bermain yaitu dengan lompatan dengan gerakan merubah arah dengan cepat yang masih kurang maksimal pada pemain SMA Negeri 1 Woja.

Berdasarkan dari hasil observasi di SMA Negeri 1 woja bahwa siswa yang mengikuti ekstrakurikuler bola voli di SMA Negeri 1 woja banyak yang tidak memenuhi lompatan yang sesuai dengan kriteria pemain voli pada umumnya sehingga akan berdampak pada pemain, yang terutama pada saat ingin melakukan smash ataupun block, dalam dua teknik yang berbeda ini, pemain harus bisa memenuhi lompatan yang tinggi, dan dengan gerakan-gerakan yang kurang agresif sehingga membuat pemain tidak dapat mengambil/merubah posisi tubuh mereka untuk mengambil/membaca arah bola yang di tempatkan oleh lawan. masih banyak pemain pada siswa yang mengikuti ekstrakurikuler bola voli di SMA Negeri 1 Woja kurang memiliki kemampuan otot/kemampuan fisik serta kelincahan sehingga pada saat bermain voli pemain lebih cepat mengalami kelelahan dan stamina mereka cepat habis, dengan begitu mereka harus banyak-banyak lagi diberikan latihan yang intensif untuk meningkatkan kekuatan power otot tungkai serta kelincahan pemain, untuk dapat memenuhi 2 faktor tersebut maka siswa harus memiliki kondisi fisik yang baik, Sehingga kualitas pemain semakin meningkatkan kekuatan otot tungkai adalah salah satu factor yang berperan dalam pencapaian lompatan yang tinggi, factor kondisi kekuatan otot tungkai, dengan kata lain, untuk mencapai lompatan harus ada unsur fisik terutama pada kekuatan otot tungkai yang di gunakan untuk menolak pada saat ingin melompat, dan melakukan gerakan dengan cepar dan lincah.

Kelincahan merupakan salah satu unsur kondisi fisik tubuh yang sangat prima, kelincahan juga menjadi bagian yang di perlukan demi memenuhi kondisi fisik yang maksimal untuk atlit voli. kelincahan juga sangat penting untuk melakukan gerakan dengan cepat pada saat pemain melakukan penyerangan dan pertahanan, tidak hanya dalam pertahanan dalam penyerangan juga di butuhkan kelincahan agar bisa melakukan penyerangan pada lawan, Menurut Asadi (2012) "kelincahan sebagai kemampuan untuk mempertahankan atau mengontrol posisi tubuh saat mengubah arah dengan cepat dan akurat selama serangkaian gerakan". pemain yang lincah adalah pemain yang bergerak tanpa harus menghilangkan keseimbangan dan tanpa kehilangan kesadaran. Dalam memenuhi kondisi fisik yang baik untuk mendapatkan kelincahan dan power otot tungkai, maka akan memerlukan metode latihan yang tepat dan jelas, ada banyak metode latihan yang bisa meningkatkan kelincahan dan power otot tungkai salah satunya adalah metode latihan High Intensity Interval Training (HIIT).

High Intensity Interval Training (HIIT) merupakan latihan fisik dengan intensitas tinggi, lebih cepat dari latihan biasa dan juga memiliki periode pemulihan yang cukup singkat, latihan ini merupakan latihan yang sedang banyak di lakukan oleh para atlit, dikarena latihan ini memiliki intensitas yang tinggi yang bila di lakukan dengan baik dan teratur maka akan menciptakan efek yang luar biasa terhadap perkembangan otot dan kesehatan pada tubuh manusia. Latihan kardio (kardiovaskular) dan sering di sebut latihan aerobic adalah jenis olah raga yang mudah dan banyak manfaatnya bagi kesehatan bagi tubuh kita khususnya dengan menjaga kesehatan jantung dan kebugaran jasmani para pemain/atlit voli, terdapat beberapa latihan aerobic dengan latihan lari, jogging, senam dan masih banyak lagi latihan yang bisa kita sebut High Intensity Interval Training. (Desmon Trisandi dkk: 2017:39). 
Beberapa teori yang digunakan untuk mendukung penelitian ini diantaranya:

\section{1) Permainan Bola Voli}

Permainan bola voli yang telah berkembang luas di setiap lapisan masyarakat bertujuan sebagai olah raga pengisi waktu sengang dan untuk memperoleh kegembiraan dan kesenangan. Dalam perkembanganya, sekarang permainan bola voli telah menjadi olah raga kompetitif resmi yang selalu di pertandingkan dalam setiap pesta olah raga, orientasi pembinaannya lebih mengarah pada pencapaian prestasi akan tetapi nilai rekreasi tidak akan pernah hilang dan akan selalu melekat, permainan bola voli memiliki beberapa keunggulan bila di bandingkan dengan olah raga lain, diantaranya adalah permainan ini bisa dimainkan oleh dua orang yang terkenal dengan bola voli pantai, bisa sampai enam orang yang biasa di gunakan dalam pertandingan tingkat nasional. Keunggulan lainnya adalah olah raga ini bersifat rekreasi dan menyenangkan dapat dimainkan didalam gedung maupun luar gedung dan hanya membutuhkan sedikit perlengkapan, menurut Barbara L.Viera (2000:2) bola voli di mainkan oleh dua tim beranggotakan dua sampai enam orang dalam satu lapangan yang berukuran 30 kaki ( 9 meter persegi) bagi satiap tim, dan setiap tim dipisahkan oleh sebuah net. Tujuan utama dari setiap tim adalah memukul bola kearah bidang lapangan musuh sedemikian rupa agar lawan tidak bisa mengembalikan bola

\section{2) Pengertian Bola Voli}

Permainan bolavoli merupakan permainan beregu menggunakan bola besar yang di mainkan oleh dua regu saling berhadapan, masing-masing regu enam orang. Setiap regu di perbolehkan memainkan bola didaerah pertahanannya sebanyak-banyaknya tiga kali pukulan, permainan bola voli adalah permainan yang berbentuk memukul bola di udara hilir mudik di atas net satu jaring, dengan masuk dapat menjatuhkan bola didalam petak lawan untuk mencari kemenangan dalam permainan, memantulkan bola ke udara harus mengunakan bagian tubuh yang mana saja, asalkan dengan pantulan yang sempurna saja (tidak ganda), keterampilan gerak dalam permainan bola voli adalah keterampilan gerak servis (tangan bawah dan tangan atas) passing atas dan passing bawah, smash dan block/bendungan (tunggal dan berkawan). (Sumaryoto dkk: 2014: 1).

\section{3) Power Otot Tungkai}

Menurut Sukadiyanto (2010: 146) bahwa tenaga ledak otot (power) adalah kualitas yang memungkinkan otot atau sekelompok otot untuk menghasilkan kerja fisik secara eksplosive, Power otot tungkai adalah kombinasi dari kekuatan dan kecepatan otot tungkai (explosive strength dan muscular power), mampu untuk melakukan aktifitas secara tiba-tiba dan cepat dengan mengerahkan seluruh kekuatan dalam waktu yang singkat. Power atau daya ledak merupakan suatu komponen biometric dalam kegiatan olahraga, karena daya ledak akan menentukan seberapa tinggi lompatan yang dihasilkan saat orang melakukan lompatan, seberapa jauh orang dapat melakukan tolakan serta seberapa cepat orang berlari.

\section{4) Kelincahan}

kelincahan adalah kemampuan seseorang dalam merubah arah dan posisi tubuhnya dengan cepat serta kelincahan itu sendiri merupakan salah satu komponen kesegaran motorik yang di perlukan untuk semua aktivitas yang memebutuhakan kecepatan perubahan posisi tubuh dan bagian-bagiannya". dan tepat pada waktu bergerak, tanpa kehilangan keseimbangan serta sadar akan posisi tubuh, kelincahan seorang atlet dalam merubah gerakan tubuh secara cepat merupakaan komponen dasar dalam olahraga tim atau beregu seperti basket dan sepak bola. Karena selama pertandingan, pemain melakukan gerakan seperti berlari dan merubah arah gerakan secara cepat, Karyono (2011:40, jadi kelincahan adalah salah satu kemampuan seseorang dalam melakukan gerakan atau kemampuan seseorang dalam mengubah posisi tubuh mereka dengan cepat tanpa harus kehilangan keseimbangan, kelincahan memiliki beberapa otot gerakan dengan kontraksi yang cepat dengan kontraksi otot-otot tungkai yang bisa memberikan daya tahan yang mampu memebuat gerakan itu tanpa harus menghilangkan keseimbangan, kelincahan merupakan kondisi fisik yang prima dengan itu kelincahan yang harus di penuhi oleh atlit voli dengan memenuhi latihan yang denga metode latihan, bisa di katakana bahwa kelincahan adalah suatu komponen biomotorik yang harus di tingkatkan dan di kembangkan, sependapat dengan Asadi (2012:36) "kelincahan sebagai kemampuan untuk mempertahankan atau mengontrol posisi tubuh saat mengubah arah dengan cepat dan akurat selama serangkaian 
gerakan". pemain yang lincah adalah pemain yang bergerak tanpa harus menghilangkan keseimbangan dan tanpa kehilangan kesadaran.

\section{5) Latihan}

Latihan adalah segala daya dan upaya untuk meningkatkan secara keseluruhan kondisi fisik kita untuk bisa mencapai gerakan yang tinggi, dengan proses yang di lakukan secara sistematis dengan berulang-ulang maka sangat besar harapnanya untuk bisa mendapatkan gerakan yang tinggi, di akibatkan dengan gerakan latihan yang intensitasnya yang sesuai dengan cabor yang di geluti atli kita melakukan latihan di karenakan bahwa latihan adalah suatu bentuk upaya untu bisa mencapai suatu tujuan atli dalam latihan dengan hal-hal yang baru, dan juga "latihan adalah proses yang sistematis dari berlatih atau bekerja, yang di lakukan secara berulang-ulang dengan kian hari kian menambah jumlah beban latihan atau pekerjaannya". Sependapat Menurut Mufidatul (2013) "mengatakan bahwa latihan adalah proses sistematis dari berlatih atau bekerja, yang di lakukan secara berulang dengan kian hari kian menambah beban latihan atau pekerjaannya".

Program latihan yang di berikan oleh pelatih sangatlah dalam kualitas latihan, dan Bukan hanya latihan fisik saja yang harus di latih untuk bisa mencapai prestasi yang maksimal, teknik, taktik, mental yang sangat penting untuk di latih, dan tugas utama dalam latihan adalah menggali, menyusun, dan mengembangkan konsep berlatih dengan memadukan antara pengalaan praktis dan pendekatan yang secara efektif sehinga proses melatih dapat berlangsung tepat, cepat, dan efesien, begitupun dengan prinsip latihan yang perlu diperhatikan dalam melatih, dimana sukadiyanto, dan Muluk dalam bukunya melatih fisik $(2011 ; 13)$ bahwa prinsip latihan merupakan hal-hal yang harus di taati, di lakukan atau di hindari agar terhindar dari cidera serius maupun hanya cidera ringan. Prinsip-prinsip latihan memiliki peranan penting dalam aspek fisiologis dan psikologis atlit, dengan memahami beberapa prinsip latihan maka akan memberikan dukungan pada upaya peningkatan kualitas latihan, selain dalam peningkatan kualitas dapat menghindarkan atlit pada rasa sakit atau cidera saat melakukan proses latihan. Sebagai seorang pelatih akan di katakana berhasil dan sukses dalam membina atlitnya dalam latihan jika pelatih dapat menerapkan prinsip latihan secara sitematis, secara cepat dan tepat yaitu Prinsip kesiapan (readiness), Prinsip individual, Prinsip adaptasi, Prinsip beban lebih (overload), Prinsip spesifikasi (kekhususan), Prinsip variasi, Prinsip pemanasan dan pendinginan (warm-up and cool-down).

Dimana latihan biasanya akan di awali dengan pemanasan dengan tujuan untuk bisa mempersiapkan diri fisik dan psikis olahragawan untuk memasuki olahraga inti, selain itu dengan di awali dengan pemanasan di harapkan olahragawan dapat kemungkinan terjadinya cidera dan rasa sakit. Dan pada saat akhir latihan akan di lakukan dengan pendinganan agar otot-otot yang gerak denga berat akan di lemaskan kembali dengan melakukan pendinginan. Karena pada saat melakukan latihan inti dan suplemen, aktivitasnya berat, mendadak, dan terputus-putus akan mengakibatkan konsentrasi daran terpusat pada otot-otot yang melakukan kerja, siklus terhambat, dan pembuangan sisa pembakaran menjadi lambat melaluai iktivias cooling-down proses penurunan suhu tubuh dari latihan berat ke normal tidak terjadi secra mendadak. (sukadiyanto dkk : 2013 :13), selain itu komponen latihan juga, sangat diperlukan dalam latihan seperti pendapatnya dari sukadiyanto, dkk dalam bukunya melatih fisik, $(2011 ; 25)$ bahwa komponen latihan merupakan salah satu kunci utama pelatih membawa sukses atlitnya ketingkat yang tinggi, selain itu komponen latihan menjadi salah satu patokan atau tolak ukur yang sangat menentukan pencapaian atau tidaknya suatu tujuan dan sasaran latihan yang telah di susun dengan terleksananya latihan dengan baik maka kemampuan atlit akan semakin meningkat, terutama pada suatu latihan yang melatih lebih dominan untuk meningkatkan unsur fisik, meliputi kualitas kebugaran otot dan kebugaran energy yang berkaitan erat dengan keadaan fisiologis, biokimia, dan fungsi organ dalam pemain.

Menurut Musyafidah dan Mintarto (2011) "mengatakan bahwa kondisi fisik merupakan komponen yang sangat penting dalam dunia olahraga tak terkecuali dalam olahraga bola voli pantai terdapat unsur-unsur yang sangat mendukung untuk meningkatkan kemampuan atlit saat bermain bola. Kondisi fisik sangat di perlukan oleh seorang atlit karna tanpa di dukung oleh kondisi fisik yang prima maka pencapain prestasi puncak akan mengalami banyak kendala, 
dan mustahil dapat prestasi tinggi" apabila tidak didukung oleh Kekuatan ( streght), Daya tahan (endurance), Daya otot (Muscular power), Kecepatan (speed), Daya lentur (flexibility), Kelincahan (agility), Koordinasi (coordination), Keseimbangan (balance), Ketepatan (Accuracy), dan Reaksi (Reaction).

\section{6) Metode Latihan High Intensity Interval Training ( HIIT )}

High Intensity Interval Training (HIIT) adalah latihan kardio (kardiovaskular) yang mengunakan kombinasi latihan dengan intensitas tinggi dengan intensitas sedang/rendah dalam selang waktu alias interval tertentu. Latihan kardio dengan metode ini dapat meningkatkan perkembangan serabut otot cepat (fast twitch fiber) yang banyak di manfaatkan oleh atlet nonketahanan (yang bermain dalam olah raga yang tidak mengandalkan stamina, seperti browling, golf, dan bela diri) untuk meningkatkan memori otot, serabut otot cepat juga menambah kecepatan dan kekuatan otot tubuh sehingga akan membuatmu bertambah gesit dan lincah. Latihan dengan intensitas tinggi akan memacu kerja jantung mu dengan lebih keras, sehingga konsumsi oksigen dalam tubuh kamu ikut meningkat, seiring dengan komsumsi oksigen yang meningkat, proses metabolism dalam tubuh juga akan semakin cepat, proses metabolism yang meningkat ini tidak hanya berlangsung ketika berolah raga. Saat kita memasuki jeda (interval) buat istirahat pun, metabolisme kita akan tetap berlangsung cepat, dari pengertian High Intensity Interval Training (HIIT) yang sudah di uraikan di atas dapat di simpulkan bahwa latihan HIIT adalah cara kita melatih tubuh kita dengan gerak-gerakan sederhana tetapi memberikan rangsangan otot kita yang baik, sehinga dalam latihan ini otot-otot kita akan semakin banyak dalam reaksi yang baik di karenakan dalam gerakan HIIT tubuh kita akan membakar lemak dalam beberapa menit gerakannya bisa membakar lebih banyak lemak bahkan sesudah olah raga pun pembakaran lemak tetap akan berjalan selam 24 jam.

Dengan penguasaan metode latihan yang baik maka atlit akan memiliki kemampuan gerak yang sempurna, dengan demikian atlit akan bisa memenuhi kekuatan gerak denga sangat cepat dan tepat dengan teknik yang baik dan sempurna. Oleh karena itu latihan sangatlah penting bagi atli untuk bisa mencapai tujuan yang sudah di targetkan. Dengan pembuatan metode latihan di harapkan kepada pemain agar bisa memahami dasar-dasar latihan agar bisa lebih mudah dalam melakukanya, menurut Gibala et al (2012) "di antara berbagai modalitas pelatihan, pelatihan interval tinggi (HIIT) di akui sebagai strategi pelatihan yang efisien waktu untuk menginduksi adaptasi yang serupa atau bahkan lebih unggul di bandingkan dengan pelatihan berkelanjutan intensitas sedang moderat menurut sejumlah fisiologis, kinerja dan kesehatan penanda terkait".

\section{METODE PENELITIAN}

Jenis penelitian yang di gunakan adalah penelitian eksperimen pendekatan kuantitatif, penelitian yang di gunakan ini untuk mencari pengaruh perlakuan tertentu terhadap yang lain dalam kondisi yang terkendali (sugiyono:2013:107), Sedangkan menurut sumadi, (2013:88) bahwa eksperimen sungguhan (research) untuk menyelidiki kemampuan saling hubungan sebab-akibat dengan cara mengenakan satu atau lebih kelompok eksperimental satu atau lebih kondisi perlakuan dan memperbandingkan hasilnya atau lebih kelompok kontrol yang tidak di kenai kondisi perlakuan, dari urain tersebut dapat di pahami bahwa penelitian eksperimen adalah penelitian yang dilakukan untuk mengetahui pengaruh pemberian suatu treatment atau perlakuan terhadap subjek penelitian, sebelum itu diperlukan suatu desain penelitian, Desain penelitian merupakan rencana tentang cara mengunakan dan menganalisis data supaya dapat dilaksanakan secara ekonomis serta serasi dengan tujuan penelitian itu, penelitian ini melibatkan dua kelompok responden yang masing-masing ditetapkan sebagai kelompok eksperimen dan kelompok control, pada kelompok eksperimen diberikan perlakuan dengan menggunakan pendekatan saintifik sedangkan kelompok kontrol tidak diberikan perlakuan, penelitian ini dilakukan dengan menggunakana pre-test, posttest one group design, dalam penelitian ini, hubungan sebab akibat dapat diketahui secara pasti karena adanya perlakuan yang dilakukan peneliti terhadap kelompok eksperimen, desain penelitian dapat dilihat dalam tabel berikut: 
Tabel 1. Desain Penelitian yang digunakan

\begin{tabular}{cccc}
\hline Kelompok & Pre-test & Perlakuan & Post-test \\
\hline Eksperimen & 01 & $\mathrm{X}$ & 02 \\
\hline Kontrol & 01 & & 02 \\
\hline
\end{tabular}

Pengumpulan data yang digunakan dalam penelitian ini adalah dengan teknik dokumentasi dan teknik test perbuatan.

Tabel 2. Daftar Tim Bola voli Sma Negeri 1 Woja

\begin{tabular}{cccc}
\hline No & Kelas & Jumlah siswa putra & Jumlah \\
\hline 1 & $\mathrm{X}$ & 13 & 13 \\
\hline 2 & $\mathrm{XI}$ & 17 & 17 \\
\hline 3 & $\mathrm{X}$ & 7 & 7 \\
\hline 4 & $\mathrm{XI}$ & 4 & 4 \\
\hline & & Jumlah & $\mathbf{4 1}$ \\
\hline
\end{tabular}

Sedangkan Instrumen penelitian digunakan dalam penelitian ini diantaranya: Vertical Jump, T-Test, instrument tersebut digunakan untuk mengukur nilai variabel yang diteliti.

Tabel 3. Kriteria Instrument Vertical Jump

\begin{tabular}{ccc} 
Rating & Laki-laki & Perempuan \\
Excellent & $>70$ & $>60$ \\
\hline Sangat baik & $61-70$ & $51-60$ \\
\hline Baik & $51-60$ & $41-50$ \\
\hline Cukup & $41-50$ & $31-40$ \\
\hline Sedang & $31-40$ & $21-30$ \\
\hline Kurang & $21-30$ & $11-20$ \\
\hline
\end{tabular}

Tabel 4. Kriteria Instrument T-Test

\begin{tabular}{|c|c|c|c|c|}
\hline \multirow{2}{*}{} & Rating & $\begin{array}{c}\text { Males } \\
\text { (seconds) }\end{array}$ & $\begin{array}{c}\text { Females } \\
\text { (seconds) }\end{array}$ \\
\cline { 3 - 5 } & & Excellent & $<9.5$ & $<10.5$ \\
\cline { 2 - 5 } & Good & $9.5-10.5$ & $10.5-11.5$ \\
\cline { 2 - 5 } & Average & $10.5-11.5$ & $11.5-12.5$ \\
\cline { 2 - 5 } & Poor & $>11.5$ & $>12.5$ \\
\hline
\end{tabular}

\section{HASIL DAN PEMBAHASAN}

Dalam permainan bola voli teknik lompat dan gerak dengan cepat adalah salah satu teknik yang berperan penting dalam melakukan serangan, Namun dalam kenyataannya dalam permainan sekarang mereka lebih mengandalkan teknik pergelangan tangan mereka untuk mengarahkan bola melewati blocker lawan, walaupun mereka tidak memiliki lentingan lompatan yang tinggi, dalam melakukan lompatan baik untuk melakukan smash ataupun block akan dilihat dari segi keakuratan dalam melakukanya baik keakuratan smash dan keakuratan dalam membendung/block smash dari lawan sehingga bisa menguntungkan tim nya, kita dalam keadaan darurat ketika bola yang begitu mendadak maka dengan begitu pergerakan kita harus cepat dan akurat dengan tidak kehilangan keseimbangan tubuh sehingga bisa mampu melakukan serangan balik degan cepat, dalam hal ini faktor yang mendukung dua hal tersebut di butuhkan latihan fisik maupun latihan mental, dengan begitu atlit akan lebih mengembangkan potensinya jika diberikan latihan dengan teratur dan sesuai 
dengan kebutuhan atlit.

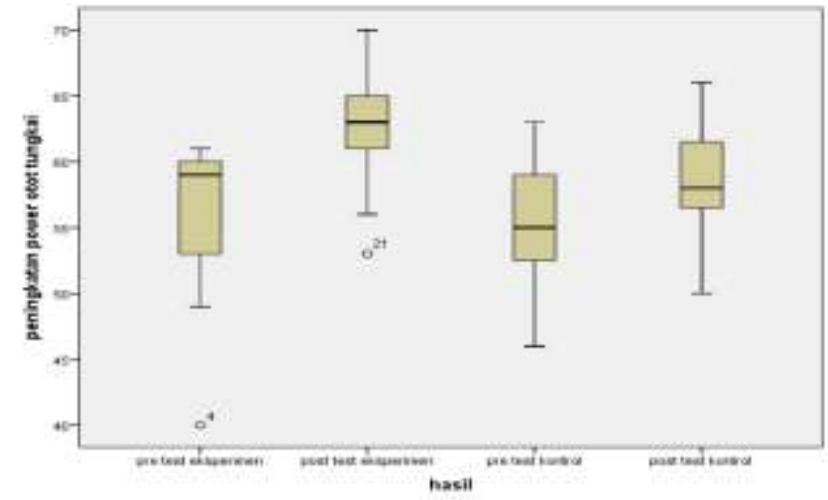

Gambar 1. Diagram Power Otot Tungkai Pemain

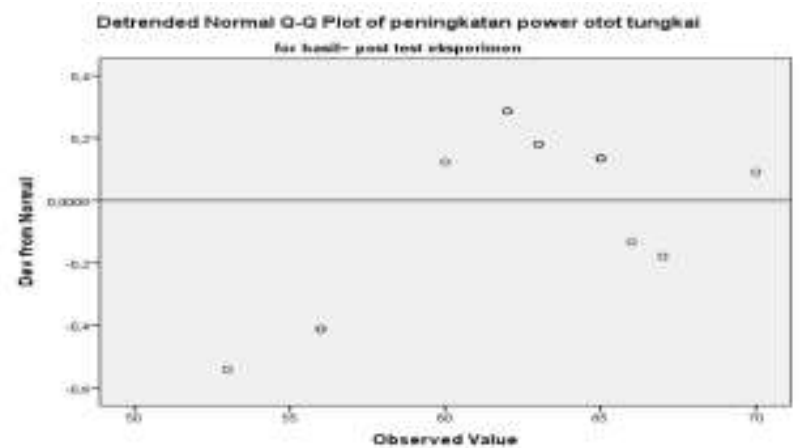

Gambar 2. Diagram Peningkatan Power Otot Tungkai

Berdasarkan analisis data hasil penelitian diperoleh peningkatan yang signifikan terhadap kelompok yang diteliti, pemberian perlakuan selama 9 kali pertemuan termasuk pretes-postetst dengan frekuensi 2 kali seminggu memberi pengaruh terha dap peningkatan power otot tungkai dan kelincahan gerak hal ini di buktikan dengan hasil uji normalitas, uji homogenitas dan uji hipotesis/uji t, Latihan High Intetsity Interval Training (HIIT) akan sangat berpengaruh dalam meningkatakan kekuatan power otot tungkai maupun dalam meningkatkan kelincahan gerak pemain latihan HIIT ini akan berpengaruh positif jika latihan ini menjadi satu kesatuan dalam suatu program latihan permainan bola voli yang rutin untuK meningkatkan kualitas pemain.
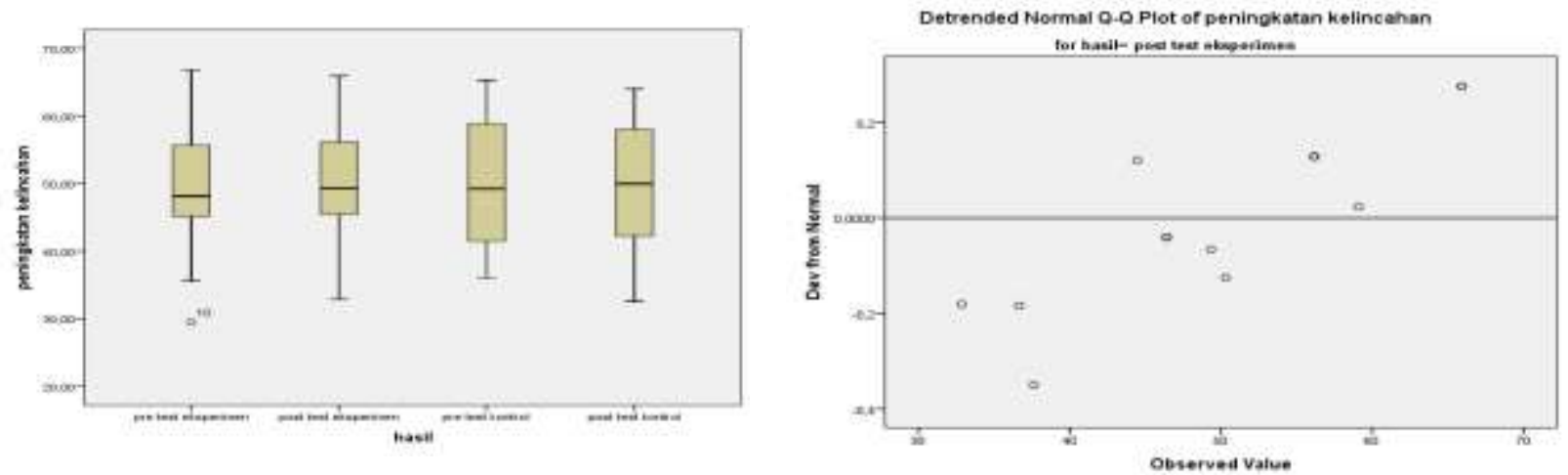

Gambar 3. Diagram Kelincahan dan Peningkatan Kelincahan Gerak Pemain

Dari hasil analisis data hasil penelitian diperoleh peningkatan yang signifikan terhadap kelompok yang diteliti, pemberian perlakuan selama 9 kali pertemuan termasuk pretes-postetst dengan frekuensi 2 kali seminggu memberi pengaruh terhadap peningkatan power otot tungkai dan kelincahan gerak hal ini di buktikan dengan hasil yang di peroleh dari diagram diatas bahwa dengan memberikan latihan yang rutin maka akan bisa memberikan perubahan dalam tingkat permainan pemain, yang artinya latihan High Intensity Interval Training memberikan pengaruh 
yang signifikan terhadap peningkatan power otot tungkai dan kelincahan pada tim bola voli putra SMAN 1 Woja.

Keefektifan terhadap metode latihan yang di kembangkan dengan berbagai gerakan dalam satu metode latihan memberikan hasil yang maksimal pada perkembangan permainan siswa dalam bentuk ketinggian lompatan dan kecepatan siswa dalam melakukan perpindahan gerakan yang baik dalam melihat ruang kosong yang akan di tempatkan oleh lawa bola, rekasi siswa dalam menierima perlakuan latihan ini pun sangat baik siswa baik dalam latihan yang di terapkan selama 2 bulan, hal ini di buktikan dengan hasil pre test mennjukan dari 30 siswa nilai rerata hnya di dapatkan $48 \%$ sedangkan pada saat post test seluruh siswa tuntas baik secara individu maupun dalam berkelompok dengan rerata nilai 95\%, dengan perolehan nilai rata-rata di atas 0,05 dengan kriteria nilai yang di dapatkan siswa dalam latihan lebih tinggi dari 0,05, hal ini mengatakan bahwa metode latihan high intensity interval training sengat efektif untuk di berikan kepada pemain voli untuk bisa meningkatkan kualitas bermain mereka, bisa di lihat pada latihan siswa SMAN 1 WOJA mereka mencapai hasil yang maksimal.

\section{SIMPULAN}

Berdasarkan hasil penelitian yang telah dilakukan, maka dapat disimpulkan bahwa metode latihan high intensity interval training yang yang di terapkan kepada siswa terbilang sangat efektif untuk bisa meningkatkan kualitas mereka saat bermain bola voli atau menjadi sebuah metode yang harus di terapkan oleh mereka untuk bisa mencapai permainan yang lebih maksimal lagi.

\section{DAFTAR RUJUKAN}

Arikunto, Suharsimi. 2013. Prosedur Penelitian "Suatu Pendekatan Praktek".Jakarta: Rineka Cipta

Ahmadi, N. 2017. Panduan Olahrga Bola Voli.Solo:Pustaka Utama

Fajrin, N W Kusnanik, 2018. effects of high intensity interval training on increasing explosive power, speed, and agility. Jurnal of physica: conference

Haryanta, Tri Agung. 2017. Kamus pendidikan jasmani, olahraga dan kesehatan. Surakarta: PT. Aksarasinergi media

Irfandri, vaniko 2013. hubungan kekuatan otot tungkai dan kelincahan terhadap kecepatan mengiring bola. Lampung. jurnal kampus universitas lampung.

Jannah, M. (2016). Perbedaan Kombinasi Dynamic Stretching Dan Latihan Lari Zig-Zag Terhadap Kelincahan Pemain Futsal. Skripsi. Program Studi Fisioterapi S1 Fakultas Ilmu Kesehatan Universitas 'Aisyiyah Yogyakarta.

Kurniawan, F. (2011). Buku Pintar Olahraga Jakarta: Laksar Aksara.

Komarudin. 2016. penilaian hasil belajar, pendidikan jasmani dan olah raga. Jakarta: PT. Remaja rosdakarya

Winarno, (Ed). 2013. Teknik dasar bermain bola voli. Malang: Bahan Penataran Wasit Nasional.

Nungraha, Muhammad, 2010. bermain voli. Sukoharjo: Prima Media.

Nanadits. 2010. Mengenal olahrags voli. Bandung: quadra.

Nala, (2011). Prinsip Latihan Fisik Olahrga. Denpasar:Universitas Udayana Granfindo Media Pratama.

Permana, Yoga. 2008. bermain dan olah raga bola volley. Surabaya: Ihsan Cendekia.

Sain, Kp. 2011. Buku saku biologi. Jakarta: PT. Kawan pustaka. 
Satria, haris, (Eds). 2016. pengaruh latihan power otot tungkai terhadap peningkatan tendangan jarak jauh sepak bola. Jurnal ilmiah ISSN :1997-8598 (VOL.9 NO.1 2016)

Sumaryoto, (Ed). 2014. pendidikan jasmani olahraga dan kesehatan. Jakarta: Kementerian pendidikan dan kebudayaan.

Sukadiyanto, (Ed). 2011. Pengantar teori dan metodelogio melatih fisik. Bandung: studio LBA.

Santosa, D.W. (2015). Pengaruh Pelatihan Squat Jump Dengan Metode Interval Pendek Terhadap Daya Ledak (Power) Otot Tungkai. Jurnal Kesehatan Olahraga. 3.(1). 158-164.

Sugiyono. 2013. Metodologi Penelitian Pendidikan. Bandung:Alfabeta.

Subroto T, Yudiana, Y. 2010. Permainan bola voli. Bandung:FPOK UPI.

Widhiyanti, Komang Ayu Tri, dkk. (2013). Pelatihan Pliometrik Alternate Leg Bound dan Double Leg Bound Meningkatkan Daya Ledak Otot Tungkai Pada Siswa Putra Kelas VII SMP NEGERI 3 SUKAWATI Tahun Pelajaran

Enung Nurhasanah. (2021). Pengembangan Multimedia Pembelajaran Sejarah Perkembangan Islam Berbasis Macromedia Flash untuk Meningkatkan Hasil Belajar Mahasiswa. Ainara Journal (Jurnal Penelitian Dan PKM Bidang Ilmu Pendidikan),2(3), 148-153. Retrieved from http://journal.ainarapress.org/index.php/ainj/article/view/69 